\title{
DEVELOPMENT OF MARKETING STRATEGIES IN BULGARIAN ENTERPRISES
}

\begin{abstract}
Dilyana Yaneva 1
Received: 01.09.2020, Accepted: 01.10.2020

Abstract

The development of an effective marketing strategy is the basis for the formation of a reliable marketing policy of the organization. At the same time, the specifics of each individual marketing strategy allows making the right decisions according to the company's goals, resources and opportunities, market situation and consumer requirements. In this regard, the article aims to examine whether Bulgarian companies have developed marketing strategies and how they are perceived by company management. The results of the opinion of Bulgarian managers and business owners are presented on the basis of a survey conducted in 2019.
\end{abstract}

Keywords: marketing strategy, types, development, decision-making process

JEL Codes: M10, M30, M31

\section{Introduction}

The modern concept for managing the marketing activities of the company includes planning, organization and control of all operations to ensure the process of reliable management decision-making for company success and development. The role of marketing planning is becoming increasingly essential in the face of increasing competition and changing consumer tastes. The process consists of two phases - analytical, concerning the determination of the current state of the organization, and perspective, related to the formulation of marketing visions for the future development of the company (Mladenova, 2006, p. 32). An important element here is the development of a marketing strategy.

The purpose of the article is to reveal the extent of marketing strategies development in the enterprises and their importance for the company management.

\footnotetext{
${ }^{1}$ South-West University "Neofit Rilski", Blagoevgrad, Faculty of Economics, Chief assist. Prof., PhD, d janeva@swu.bg ORCID ID: https://orcid.org/0000-0003-3472-4595
} 


\section{Problem statement}

„In a competitive environment, the starting point is to identify the competitive position, set business objectives, which will comprise revenue, market share and profit requirements, then formulate the strategies necessary to achieve the new position. Under these conditions, marketing strategies are the centerpiece" (Brown \& McDonald, 1994, p.1).

Pehlivanov and Kyurova (2013) define the marketing strategy as a way of action of the company on the market which formulates the main goals of the activity and the instrumentality for their achievement. It combines the goals of the company, its production capabilities and chances on the market (p.42). At the same time, the company's strategy must take into account changes in world conditions and emerging new opportunities (Kotler, 1996, p. 116). In a highly competitive environment, only companies that implement effective marketing tools become successful (Kyurova \& Yaneva, 2017, p.495). Therefore, the marketing strategy must be focused on the strategic opportunities and the creation of a sustainable competitive advantage of the company. Timofeeva (2015) draws attention to the competitive potential of the enterprise as an important element in the formation and implementation of an effective competitive strategy (p.17). Another important aspect is the orientation towards scientific and technical progress and innovation activity. In this regard, Porter (2004) emphasizes that companies will not succeed if they do not base their strategies on improvement and innovation (p.45).

It is clear that marketing strategy is a key tool for strategic marketing management. It can be said that it is a complex and powerful weapon, with the help of which modern companies can withstand the changing conditions by bringing its capabilities in line with the external environment and the market situation (Pehlivanov, 2006, p. 46-47). It is no coincidence that Kotler and Andreassen (2005) view marketing strategy not only as a way to define marketing goals and objectives, but also as a compilation of specific market goals, competitive positioning and key elements of the marketing mix forming its "core" (p.84).

On the other hand, it helps to determine the strategic positions of the company, their fuller and more effective use, their expansion and / or the creation of future favorable opportunities for development. It presents the strategic alternatives, ways and actions for achieving the set goals in a long-term period. As it reflects the general orientation of the enterprise, it should be coordinated with other functional areas and functional strategies (Madgerova et al., 2012, p.146). 


\section{Analysis and discussion}

To achieve the goal a survey was conducted among 132 managers and owners of enterprises in the field of production, trade and services on the territory of Blagoevgrad region, Bulgaria in the period June - July 2019.

Establishing the profile of enterprises is important for the study. The results of the survey show that according to the sphere of economic activity the enterprises in the sample are distributed as follows: $9.1 \%$ - production, $31.8 \%$ trade and $59.1 \%$ - services. According to the size, depending on the number of employees, the surveyed enterprises are: $52.3 \%$ - micro, $27.3 \%$ - small, $6.8 \%$ medium, $13.6 \%$ - large enterprises. According to the period of functioning of the market the distribution is as follows: $2.3 \%$ - up to 1 year, $25.1 \%-1-5$ years, $18.2 \%$ - 5-10 years, $54.4 \%$ - over 10 years.

The reliable planning of the strategic marketing activity of the company requires a study in the following aspects:

- importance of the marketing strategy for the company's success;

- availability and degree of development of marketing strategy;

- the types of marketing strategies developed in the enterprises.

Figure № 1. Importance of marketing strategy for the company success

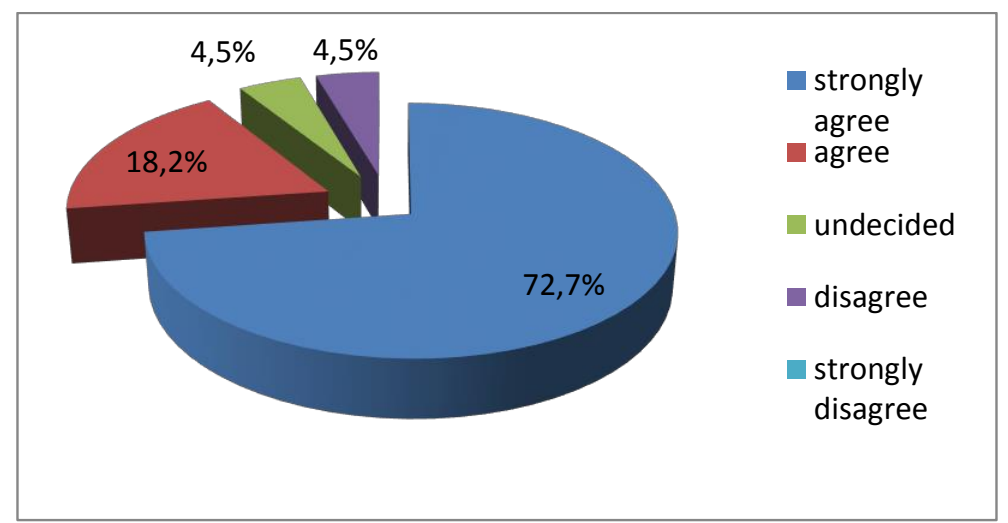

Source: own calculation based on surveys' results

Based on the data illustrated in Figure 1, it is found that the majority of respondents assess the importance of marketing strategy for the development of the organization. However, $18.2 \%$ consider it partly essential and $4.5 \%$ even insignificant. None of the respondents indicated that it has absolutely no significance for the company's success. 
Regarding to the existence of a marketing strategy, it is established that over a quarter of the enterprises in Blagoevgrad region (27.3\%) have a fully developed strategy. Figure 2 shows that in $54.5 \%$ of them it is partially developed and in $6.8 \%$ it is under development. However, the relative share of enterprises without such a strategic instrument is relatively high $-11.4 \%$.

Figure № 2. Existence and degree of development of marketing strategy in the enterprises in Blagoevgrad region

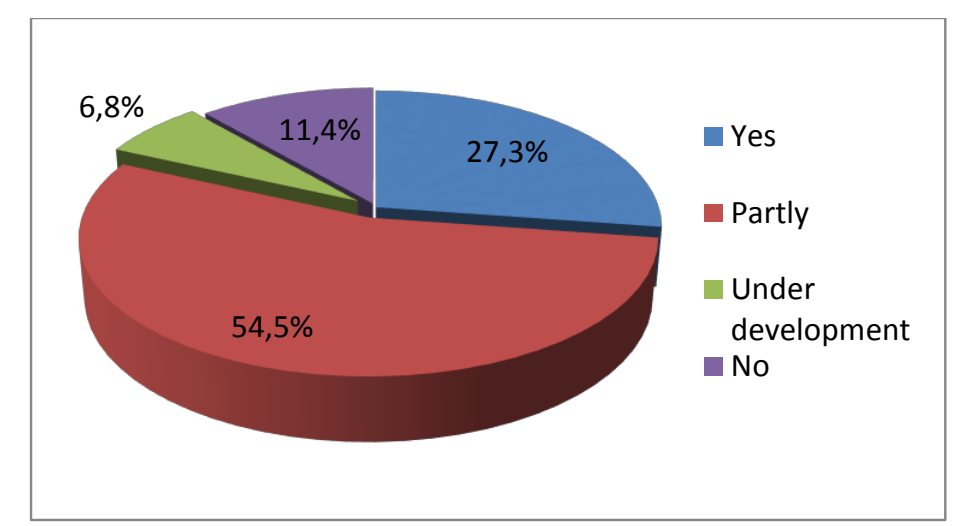

Source: own calculation based on surveys' results

The results show that in larger enterprises, the degree of strategy development is higher. Two thirds of medium and large enterprises have a fully formulated and implemented in their marketing activities strategy. For small and micro enterprises this share is $33.3 \%$ and $8.7 \%$. On the other hand, the majority of them specify that it is partly ready - 65.2\% (micro enterprises) and 58.4\% (small enterprises). There is no company with more than 50 employees that does not have a developed strategy. At the same time, its absence is found in $17.4 \%$ of micro enterprises and $8.3 \%$ of small enterprises.

Survey data also show dependence on the period in which the organization operates. It turns out that companies with many years of experience in the market pay due attention to developing a marketing strategy.

For companies established more than 10 years ago the strategy is fully completed (33.3\%), partly ready (50\%) and under development (4.2\%). A quarter of the companies operating from 5 to 10 years have a fully prepared strategy. In the remaining $75 \%$ it is partially formulated. $18.2 \%$ of the companies with 1 to 5 years of experience do not have such a document and in $45.5 \%$ it is partially 
created. None of the companies operating on the market for several months has a fully developed marketing strategy.

Refracting the issues through the sphere of economic activity, it is found that there is a strategy mainly in the commercial enterprises - fully completed in $57.2 \%$ and partly in $35.7 \%$ of them. In the field of services $73.1 \%$ of enterprises claim that the marketing strategy is almost ready. At the same time, in $50 \%$ of the enterprises in the production sphere there is such a document and in the other enterprises it is not available.

The third area in the present study concerns the types of marketing strategies developed in the organizations. The results presented in Figure 3 show that the majority of enterprises in the Blagoevgrad region consider the importance of corporate strategies related to company growth and the achievement of the general goals.

Figure № 3. Types of strategies and their importance for the company development in the enterprises in Blagoevgrad region

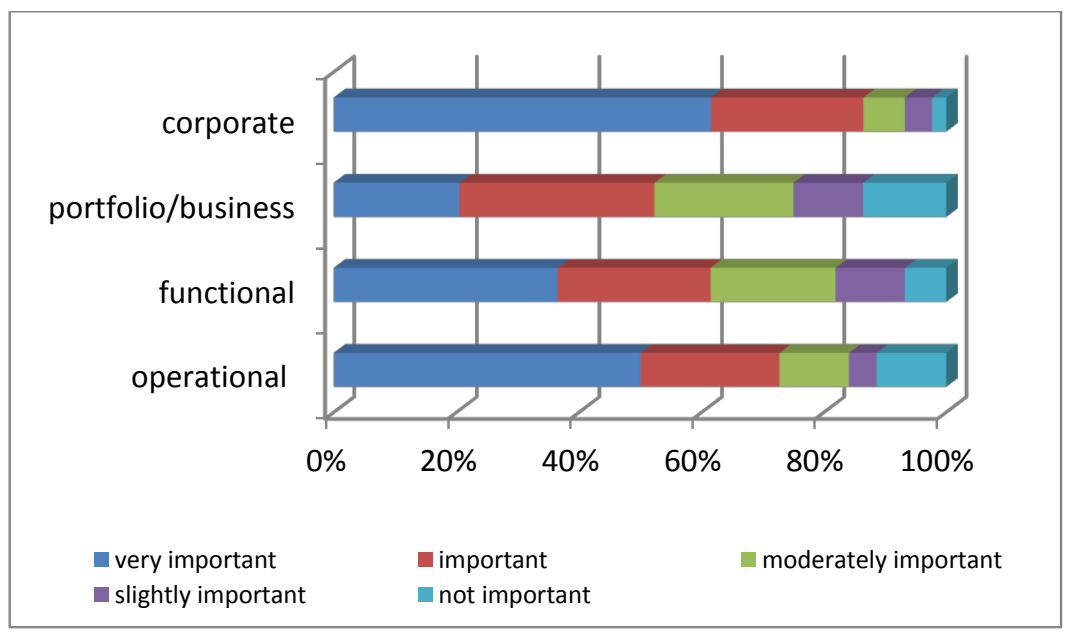

Source: own calculation based on surveys' results

For a better understanding of the issue, the developed strategies in the different types of enterprises are examined. Growth strategies are found to be a priority for $41.7 \%$ of micro-enterprises. Equally respondents pay attention to competitive strategies. Their size determines the fact that they do not develop 
business strategies. Small enterprises have an affinity for functional (75\%), corporate $(58.3 \%)$ and operational strategies $(58.3 \%)$. For the medium-sized enterprises a leading role is played by the corporate and operational strategies. Strategic decisions concerning products, prices, distribution and communications are at the forefront in $66.7 \%$ of large companies.

The results of the study show that the leading role in the management of companies established over several months are the strategies related to increasing and maintaining market share, entering new markets, gaining a competitive advantage and market segmentation. Enterprises established less than 10 years ago focus mainly on market development strategies. Most companies (58.3\%) with more than 10 years of experience are aware of the importance of the marketing mix in making strategic decisions.

The data reveal that growth strategies are most important for $69.2 \%$ of enterprises in the service sector, $78.6 \%$ - of those in trade and $75 \%$ of manufacturing enterprises. Every third manufacturing company mentions that it develops mainly competitive strategies. The development of business strategies is not directly related to the subject of company activity. That is why the same degree of development of this type of strategies is established in the enterprises in Blagoevgrad region. The formulation of functional strategies is present in 50\% of manufacturing companies, $57.7 \%$ of service providers and $64.3 \%$ of commercial enterprises. Operational strategies are most widely applicable in the field of trade $-71.4 \%$ of respondents.

\section{Conclusions}

Based on the above, we can conclude that more and more managers understand the need to develop a marketing strategy as a key tool for achieving corporate goals and company prosperity. However, the share of companies that have developed an entirely marketing strategy is small. Most of them have developed individual elements of it.

All types of strategies are being developed in the enterprises in Blagoevgrad region. Priority is given to marketing decisions concerning the conquest of new markets, strengthening the market position, building lasting competitive advantages, increasing profitability, redistribution of resources between SBU, the formation of a portfolio of structural company divisions, market segmentation, product positioning and marketing mix. 


\section{REFERENCES}

Brown, L. \& McDonald, M. (1994). Competitive Marketing Strategy: Concepts and Application, Competitive Marketing Strategy for Europe, Palgrave, London, 1-71.

Kotler, P. \& Andreasen, A. (2005). Strategic marketing for non-profit organizations. Sofia: Classics and style.

Kotler, P. (1996). Marketing management. Sofia: Grafema.

Kyurova, V. \& Yaneva, D. (2017). Research on the impact of the corporate image on the competitiveness of interior design enterprises, $C B U$ International Conference Proceedings, 5, Prague, Czech Republic, 495-498.

Madgerova, R. et al. (2012). Organization and management of small business. Blagoevgrad: Langov.

Mladenova, G. (2006). Marketing planning. Sofia: University for national and world economy Publishing House.

Pehlivanov, V. \& Kyurova, V. (2013). Basic marketing issues. Sofia: Galik.

Pehlivanov, V. (2006). Marketing course. Sofia: Galik.

Porter, M. (2004). The competitive advantage of nations. Sofia: Classics and style.

Timofeeva, S. (2015). Competitive potential of enterprise - elements, model and guidelines for development, Entrepreneurship, 1, Blagoevgrad: South-West University Publishing House, 16-30. 